\title{
Biodegradable Shape Memory Polymers- A Mini Review
}

\author{
Sangeetha $\mathrm{K}^{1}$, Aisverya $\mathrm{S}^{1}$, Jisha Kumari $\mathbf{A V}^{2}$, Anil Sukumaran ${ }^{3}$ and Sudha $\mathrm{PN}^{1 *}$ \\ ${ }^{1} P G$ and Research Department of Chemistry, DKM College for Women, India \\ ${ }^{2}$ Department of Chemistry, Tagore Engineering College, India \\ ${ }^{3}$ Dental Health Department, King Saud University, Saudi Arabia
}

Submission: November 09, 2017; Published: December 20, 2017

*Corresponding author: Sudha PN, PG and Research Department of Chemistry, DKM College for Women, Vellore, Tamil Nadu, India, Tel: (+91) 98429 10157; Email: drparsu8@gmail.com

\begin{abstract}
The use of degradable polymers in medicine was rapidly expanding from the last decade. The introduction of biodegradable polymers with shape memory effect has come into existence very recently. Biodegradable shape memory polymers are promising materials for the design of biomedical scaffolds which will allow degradation and tissue repair with minimal intervention. On comparing to shape memory alloys and ceramics, the development of degradable shape memory polymers will evade the limitations of subsequent surgical procedures for implant extraction. This paper glances over the general aspects of the different types of stimuli that will activate the shape memory effect and also addresses the applications of biodegradable SMP's as medical devices.
\end{abstract}

Keywords: Stimuli; Stents; Bone graft; Artificial disc; Biodegradable polymers

\section{Introduction}

Shape memory biodegradable polymer was a new class of smart materials which have become increasingly important among research community and has been explored in various applications including cardiovascular, robotic, dental and so on. Around $70 \%$ of patents on biodegradable SMP's were focused on applications in biomedicine such as cardiology, orthopedics and hematology. The shape memory polymers can be defined as the materials that can be programmed into a temporary shape, and upon applications of external stimulus return to a permanent shape [1]. It may adopt one (dual-shape), two (triple-shape) or several (multi-shape) stable temporary shapes and recover to their permanent shape by applying trigger such as heat, light, temperature, $\mathrm{pH}$ etc [2]. The schematic representation of dimensional changes of polymeric systems upon different stimuli and their resulting response were shown in Figure 1. In this review we have explored the biomedical application of degradable shape memory polymers [3]. For evaluating the suitability of shape memory polymers in biomedical field the following factors should be considered as follows: trigger mechanism, biocompatibility, mechanical properties and the performance of shape memory effect [4]. The schematic representation of the basic design consideration in biomedical field was shown in Figure 2.

\section{Biodegradable SMP's in Biomedical Application}

Potential application of biodegradable shape memory polymers were successfully explored in drug delivery, wound healing, tissue engineering, endovascular clot removal and biomedical devices as stents, catheters etc. For biodegradable SMP's, the switching temperature should be close or slightly above body temperature. The replacement of non-degradable SMP's by biodegradable one will provide a new pathway that reduce the risk of side effects and improve the quality of life.

The use of metallic stents as scaffold will have the limitation of in-stent restenosis and thrombosis [5]. This metal stents are prone to re-narrowing of the artery after 6 months, however the incorporation of degradable shape memory polymeric stents will eliminates the requirement of secondary operation as the removal of stent material was not needed. One of the first reported biodegradable SMP's stent was Igaki-Tamai stent (made of Poly-L-lactic acid) and have been shown to be effective in the coronaries [6]. The PLLA stent fully degraded within 3 years and also supports long-term safety of the stent. Some other examples of degradable polymeric stents include polyvinyl alcohol (PVA), polyethylene glycol (PEG) and Polylactic acid (PLA). Sonawane et al. [7] developed bio-absorbable polymeric stent using 
the combination of PLA, PLGA and reported the stent as good compatibility with blood. Another interesting biocompatible shape memory drug-eluting stent reported in recent year was cross linked polyethylene glycol (PEG)-PCL copolymer network which have the melting temperature close to body temperature sustainably release mitomycin $\mathrm{C}$ and curcumin after shape memory performance [8]. Xioa et al. [9] reported potential drug- eluting stent using cross-linked poly ( $\varepsilon$-caprolactone) (CPCL) and poly (sebacic anhydride) (PSA). Biodegradable shape memory stent based on chitosan films was reported by Chen et al. [10] that can be placed in artery with minimal surgical invasion. In another study Chen [11] and his coworkers reported genipincross linked chitosan polymeric stent

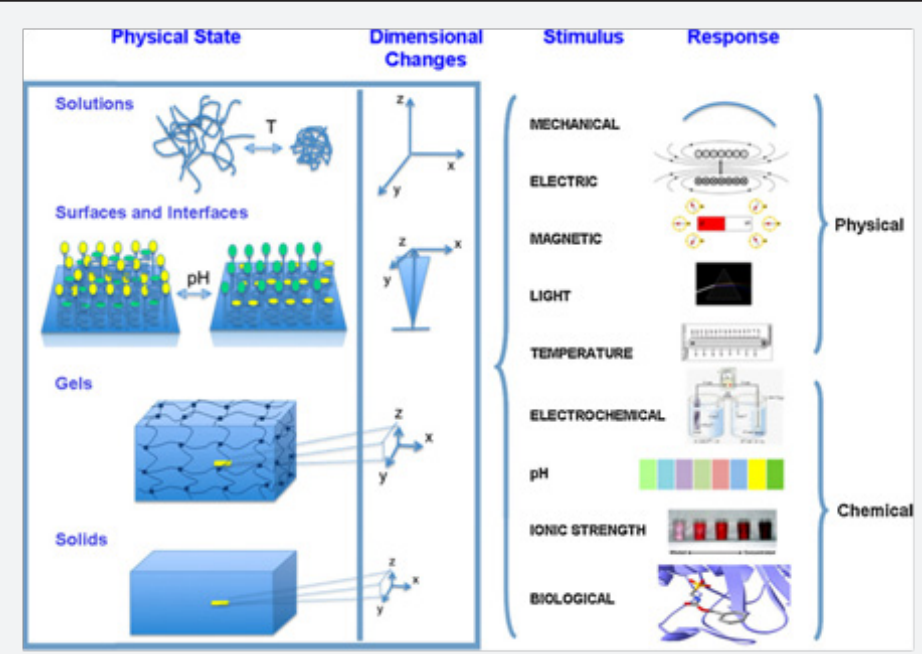

Figure 1: Schematic representation of dimensional changes of polymeric systems upon different stimuli and their resulting response [3].

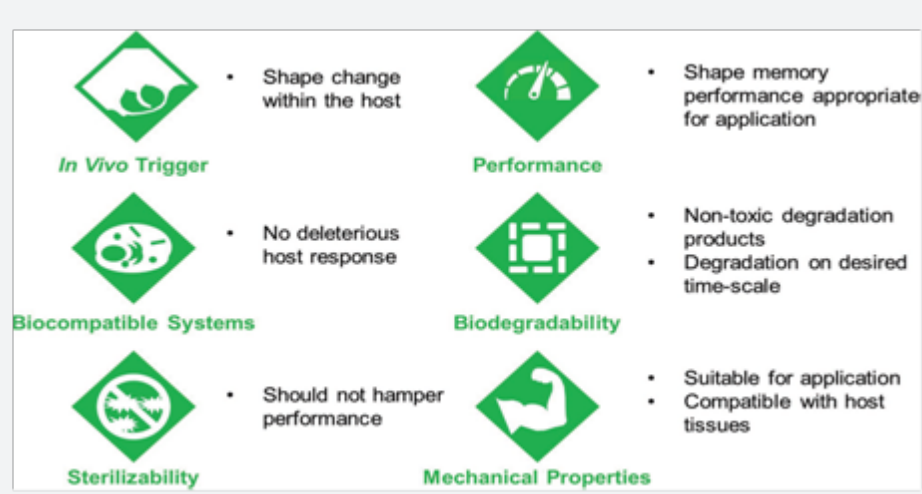

Figure 2: Schematic representation of the basic design consideration in biomedical field [4].

When applying non degradable polyurethane based SMP graft for segmental bone defects it should integrated with post surgery after 12 weeks providing torsional stability comparable to an allograft. Whereas on switching to degrable SMP's for bone defects will results in fast healing of grafted bone and also the post surgery should be avoided on employing degrable SMP's [12]. Xu et al. [13] developed biodegradable amorphous SMP using polyhedral oligomeric silsesquioxane (POSS) nanoparticle core and 8 poly (DL-lactide) (PDLA) arms. This POSS-SMP nanocomposites, with cortical bone like moduli was implaned for male rats and examined after one year of implantation. Xu et al. [13] and his coworkers reported this degradable polymeric scaffold was a potential candidate for tissue repair and no pathologic abnormalities were detected after 1 year. Biodegradable SMP's as $2 \mathrm{D}$ and $3 \mathrm{D}$ scaffolds were reported in recent years for tissue engineering application [14]. The primary motto of tissue engineering is the regeneration of new tissues that will act as a substitute to maintain and improve the functions of tissue [15]. These manmade bio-mimetric degradable polymers with shape memory effect will support the development of tissues and their growth. The accordion-like striped actuators made of liquid crystal polymer films with shape memory effect was developed by De Haan et al. [16] which would be used in medical systems and microrobotics.

Chronic recording of brain activity was anchored using epoxy based materials which is non-degradable in nature. When it was switched over by degradable shape memory polymers, it was more compatible with the brain tissues thereby reducing trauma and facilitates the removal of probe once the brain monitoring was completed [17]. Zhang et al. [18] has developed artificial 
spinal disc using biodegradable SMP containing polyethylene glycol (PEG) and poly (lactic acid) or poly (lactic-co-glycolic acids). This artificial spinal disc looks as softer material which was manipulated easily and installed. After recovering its shape in between the vertebrates, the disc would stiffen for enhance weight-bearing performance.

\section{Conclusion}

The application of biodegradable polymers with shape memory effect may usher in an era of simple, low cost biocompatible smart materials that expanded the scope and clinical utility of these materials. The majority of applications were in pilot developmental stages and hence these degradable biocompatible materials with dynamic properties were explored more in future that may helps in diverse application in this material world.

\section{References}

1. Kempaiah R, Nie Z (2014) From nature to synthetic systems: shape trans-formation in soft materials. J Mater Chem B 2: 2357-2368.

2. Karger-Kocsis J, Kéki S (2014) Biodegradable polyester-based shape memory polymers: Concepts of (supra) molecular architecturing. eXPRESS Polymer Letters 8(6): 397-412.

3. Liu F, Urban MW (2010) Recent advances and challenges in designing stimuli-responsive polymers. Progress in Polymer Science 35(1-2): 3-23.

4. Chan BQY, Low ZWK, Heng SJW, Chan SY, Owh C, et al. (2016) Recent advances in shape memory soft materials for biomedical applications. ACS Appl Mater Interfaces 8(16): 10070-10087.

5. Bonan R, Asgar AW (2009) Interventional cardiology biodegradable stents- where are we in 2009? Interventional cardiology 6(1): 81-84.

6. Tamai H, Igaki K, Kyo E, Kosuga K, Kawashima A, et al. (2000) Initial and 6-month results of biodegradable poly-L-lactic acid coronary stents in humans. Circulation 102(4): 399-404

7. Sonawane VC, More MP, Pandey AP, Patil PO, Deshmukh PK (2017) Fabrication and characterization of shape memory polymers based bioabsorbable biomedical drug eluting stent. Artificial cells Nanomed and Biotechnol 45(8): 1740-1750.
8. Yang CS, Wu HC, Sun JS, Hsiao HM, Wang TW (2013) Thermoinduced shape-memory PEG-PCL copolymer as a dual-drugeluting biodegradable stent. ACS Applied Materials \& Interfaces 5(21): 1098510994.

9. Xiao Y, Zhou S, Wang L, Zheng X, Gong T (2010) Cross-linked poly( $\varepsilon$ caprolactone)/poly(sebacic anhydride) composites combining biodegradation. controlled drug release and shape memory effect. Composites: Part B 41(7): 537-542.

10. Chen M, Tsai H, Chang Y, Lai W, Mi F, et al. (2007) Rapidly self-expandable polymeric stents with a shape-memory property. Biomacromolecules 8(9): 2274-2280.

11. Chen M, Liu C, Tsai H, Lai W, Chang Y, et al. (2009) Mechanical properties, drug eluting characteristics and in vivo performance of a genipin-crosslinked chitosan polymeric stent. Biomaterials 30(29): 5560-5571.

12. Baker RM, Tseng L-F, Iannolo MT, Oest ME, Henderson JH (2015) Selfdeploying shape memory polymer scaffolds for grafting and stabilizing complex bone defects: a mouse femoral segmental defect study. Biomaterials 76: 388-398.

13. Xu JW, Song J (2010) High performance shape memory polymer networks based on rigid nanoparticle cores. Proc Natl Acad Sci 107(17): 7652-7657.

14. Rickert D, Lendlein A, Peters I, Moses MA, Franke RP (2006) Biocompatibility testing of novel multifunctional polymeric biomaterials for tissue engineering applications in head and neck surgery: an overview. Eur Arch Otorhinolaryngol 263(3): 215-22.

15. Fakhrullin RF, Lvov YM (2016) Halloysite clay nanotubes for tissue engineering. Nanomedicine 11(17): 2243-2246.

16. De Haan LT, Gimenez-Pinto V, Konya A, Nguyen T, Verjans JMN, et al. (2014) Accordion-like actuators of multiple 3D patterned liquid crystal polymer films. Advanced Functional Materials 24(9): 1251-1258.

17. Andrew AS, Hrishikesh VP, Alicia O, Ryan A, Sarah RB, et al. (2006) Toward a self-deploying shape memory polymer neuronal electrode. J Neural Eng 3(4): L23-L30.

18. Zhang B, DeBartolo JE, Song J (2017) Shape recovery with concomitant mechanical strengthening of amphiphilic shape memory polymers in warm water. ACS Appl Mater Interfaces 9(5): 4450-4456.

\section{Your next submission with Juniper Publishers will reach you the below assets}

- Quality Editorial service

- Swift Peer Review

- Reprints availability

- E-prints Service

- Manuscript Podcast for convenient understanding

- Global attainment for your research

- Manuscript accessibility in different formats

( Pdf, E-pub, Full Text, Audio)

- Unceasing customer service

Track the below URL for one-step submission https://juniperpublishers.com/online-submission.php 